\title{
Sulfa Crystal Measurement
}

National Cancer Institute

\section{Source}

National Cancer Institute. Sulfa Crystal Measurement. NCI Thesaurus. Code C74755.

The determination of the amount of sulfa crystals present in a urine sample. 